\title{
La lectura: placer de los estudiantes
}

\author{
Gerardo Cardozo-Rincón ${ }^{*}$
}

Doctor en Filosofía y Lingüística.

Universidad Pedagógica y Tecnológica de Colombia, Tunja, Colombia.

Correo electrónico:

gerardo8202@hotmail.com.

Recibido: 28 de noviembre del 2014

Aprobado: 11 de mayo del 2015

Cómo citar este artículo: CardozoRincón, Gerardo. "La lectura: placer de Ios estudiantes". Rastros Rostros 17.31 (2015): 89-97. Impreso. doi: http://dx.doi. org/10.16925/ra.v17i31.1098

\section{Resumen}

Propósito: en este artículo se darán a conocer los resultados de una investigación que se desarrolló con estudiantes de bachillerato en un municipio de Boyacá, Colombia. El trabajo tuvo como objetivo principal propiciar la lectura, puesto que se considera esencial en la formación integral de las personas. Descripción: se ha pensado de manera crítica en algunas ideas compartidas y repetidas acerca de la lectura en el ámbito académico. Esto llevó a que, en la fundamentación teórica, se le haya dado protagonismo a algunos planteamientos que permiten rescatar la concepción de la lectura como un ejercicio cargado de placer. Punto de vista: de la misma forma, de acuerdo con los resultados obtenidos, se han discutido esos planteamientos generalizados que opacan el valor artístico y placentero de esta actividad. Conclusiones: finalmente, los resultados permiten concluir que las estrategias para fortalecer la lectura no son desconocidas ni complejas, pero sí requieren de actitudes específicas, tales como el reconocimiento en el estudiante de gustos individuales, así como el replanteamiento de la lectura indiscutible de algunos libros que se consideran obligatorios.

Palabras claves: estudiantes, formación integral, lector, lectura, placer. 


\title{
Reading: The students' pleasure
}

\begin{abstract}
Purpose: this article publishes the results of a piece of research that was conducted with high school students in a municipality of Boyacá, Colombia. This work's main objective was to promote reading since it is considered essential in the comprehensive training of people. Description: some shared and repeated ideas about reading in academia have been critically considered. This led the theoretical foundation to give prominence to some approaches that revive the concept of reading as a fully pleasant exercise. Point of view: likewise, according to the results obtained, such generalized statements that obscure the artistic and enjoyable value of this activity have been discussed. Conclusions: finally, the results suggest that the strategies to strengthen reading are not unfamiliar or complex, but do require specific attitudes such as recognizing the student's individual tastes and rethinking the undisputed reading of some books considered mandatory.
\end{abstract}

Keywords: students, comprehensive education, reader, reading, pleasure.

\section{A leitura: prazer dos estudantes}

\section{Resumo}

Propósito: neste artigo serão divulgados os resultados de uma investigação que foi desenvolvida com estudantes de ensino secundário, em um município do departamento de Boyacá, na Colômbia. O trabalho teve como principal objetivo estimular a leitura, já que é considerada como essencial na formação integral das pessoas. Descrição: pensa-se de forma crítica em algumas ideias partilhadas e repetidas sobre a leitura no âmbito acadêmico. Isso provocou que, na fundamentação teórica, tenham recebido protagonismo algumas colocações que permitem resgatar a concepção de leitura como um exercício carregado de prazer. Ponto de vista: da mesma forma, de acordo com os resultados obtidos, foram debatidas essas colocações generalizadas que opacam o valor artístico e prazeroso desta atividade. Conclusões: finalmente, os resultados permitem concluir que as estratégias para fortalecer a leitura não são desconhecidas nem complexas, mas precisam atitudes específicas, tais como o reconhecimento no estudante de gostos individuais, bem como a recolocação da leitura indiscutível de alguns livros que são considerados obrigatórios.

Palavras-chave: estudantes, formação integral, leitor, leitura, prazer. 


\section{Introducción}

Es común que se escuchen críticas en relación con los bajos niveles de lectura de los estudiantes, así como es infrecuente que se escuchen propuestas dirigidas a propiciar la lectura por medio de estrategias que involucren el placer y el gusto de los alumnos. De hecho, en el contexto académico, cuando se habla del placer en la lectura, es casi inevitable que los textos propuestos tengan mucha más relación con el gusto de los profesores que con el de los discentes. Ahora bien, aunque no siempre los gustos literarios del docente sean similares a los de los estudiantes, es posible que el docente, con base en su experiencia como lector (experto o aficionado), sea el que invite a leer por medio de la presentación breve de diferentes libros. Sin duda, puede asegurarse que un estudiante promedio no sentirá interés por leer todos los libros que el profesor mencione, pero habrá uno o varios libros que despierten el interés y ese será el que un estudiante podrá leer con placer.

García Garrido sostiene que:

En todo el mundo parece haberse abierto la convicción unánime de que a los niños, a los adolescentes y a los jóvenes de hoy no les gusta leer; más todavía: la convicción de que un alto porcentaje de ellos odian la lectura, la evitan, la sustituyen siempre que pueden por otro modo de información, de ocupación, de entretenimiento. (219)

Es una generalización muy compartida, mas no toma en cuenta qué es aquello que los jóvenes no quieren leer.

Una analogía sobre este tema podría exponerse con la televisión: quizá a los estudiantes de bachillerato les guste ver televisión, pero no todos quieren ver solamente programas educativos; algunos prefieren las películas de acción; otros, las de suspenso; otros descansarán viendo novelas... En definitiva, con la analogía del libro y la televisión, se aclara la posibilidad de un estudiante que sí querría leer, pero no aquellos libros que, quizá por considerarlos clásicos, son los que se asumen como casi obligatorios en los diferentes niveles de educación. De hecho, si se quiere fomentar el hábito lector, debe acudirse al placer de la lectura; luego, cuando sea un placer, será más fácil que lo clásico también sea parte de una actividad que, de por sí, ya es placentera.

Así, se formuló una pregunta que orientó esta experiencia investigativa: ¿cómo fomentar la lectura a través de la creación de espacios en los que el placer sea el motivo principal para leer?

Con base en lo anterior, la idea consistió en fomentar el hábito lector en los estudiantes, por medio de momentos dedicados especialmente a ese ejercicio intelectual. Con esos espacios se ha pretendido identificar el papel de la lectura en la realidad de los estudiantes del nivel de básica secundaria. Del mismo modo, se ha visto qué tan placentera puede ser la lectura para los estudiantes, o si es una actividad que no les atrae. Para este propósito, se han evitado los prejuicios y las creencias generalizadas acerca de la relación entre los estudiantes y la lectura, pues ante todo se han querido dar a conocer unos resultados que, más allá de cualquier propuesta teórica, sean útiles tanto en el aula como en la vida cotidiana de los estudiantes, vistos como seres humanos en un proceso de formación integral. Con estos fundamentos, a fin de desarrollar la idea que llevó a esta investigación, se ha asumido el placer como el motor que impulsa la lectura y con el que se puede lograr que la literatura deje de ser otra imposición, y más bien se constituya, como arte, en una actividad atrayente y de gusto personal.

Básicamente, hubo dos momentos generales: la lectura de un mismo libro para todos (sugerido por el profesor) y la lectura del "libro libre". En lo referente a la etapa del "libro libre", cabe anotar que algunos estudiantes optaron por leer libros que les llamaron la atención por algún motivo personal, y otros optaron por leer uno de los libros presentados y recomendados brevemente por el profesor en la clase de español.

$\mathrm{Al}$ ver el gusto compartido que los estudiantes demostraron por la lectura, surgió un planteamiento que se contrapone a una idea generalizada. Uno de los clichés del ámbito educativo es que a los estudiantes no les gusta leer. Esto es lo que muchos profesores afirman, en especial siempre que se hace referencia a la asignatura de español. No obstante, sobre esa generalización no se conoce un estudio que la sustente. Por el contrario, tomando como base el trabajo que se quiere compartir en este artículo, se puede asegurar que a los estudiantes sí les gusta leer, y así lo corroboran las entrevistas hechas a algunos de los discentes que participaron en el proyecto de lectura. En fin, la realidad demostró que los estudiantes sienten gusto por la lectura, y si los estudiantes a veces no leen, esto no se debe a la falta de interés, sino a otros motivos tales como la ausencia de momentos y espacios dedicados estrictamente a la lectura, o la falta de motivación por parte del docente. 


\section{Fundamentación teórica}

\section{La lectura en el ámbito escolar}

En primer lugar, es importante reconocer que la lectura, como ejercicio intelectual, requiere cierto nivel de concentración y de dedicación por parte de quienes la practiquen. De todas formas, eso no es motivo para que se considere como una actividad que desagrade o que se oponga a un posible momento de placer. Podría pensarse algo parecido del ajedrez, y no cabe duda de que siempre que alguien juega ajedrez, lo hace por iniciativa y con gusto.

Niño (121) presenta una definición de lectura en la que el nivel de comprensión se asume y se sobrepasa: “(...) leer es aplicar el pensamiento a un escrito para interpretar sus signos, recuperar y valorar la información". Aunque ya es de conocimiento común que la lectura no se limita a la decodificación ni a la comprensión, no es extraño que cuando un docente quiere desarrollar ejercicios de lectura, tenga que enfrentarse con cuestiones inherentes a la decodificación y a la antipatía de los estudiantes. De hecho, algunos discentes ven la lectura como una tarea académica que les quita tiempo y no les deja hacer lo que les gusta.

Sin embargo, esa dificultad mencionada no tiene que ver con la lectura como tal, sino con lo que se lee. Maurois (citado por Ordóñez) presenta tres clases de lectura: lectura vicio, lectura placer y lectura trabajo. En la primera no hay una selección de lecturas, sino que se lee cualquier texto, todo lo que llega a las manos, a pesar de que sea algo irrelevante. En cuanto a la lectura placer, afirma que es el tipo de lectura que se debe cultivar, puesto que leer cualquier tipo de texto por placer es un ejercicio activo y sano. Por otra parte, la lectura trabajo es aquella que se realiza con el fin de lograr un aprendizaje sobre un tema específico (esta es la típica lectura del estudio).

En el contexto educativo suele ser más común la lectura trabajo. Se lee con el propósito de cumplir con unos requerimientos y aprender. Las diferentes tendencias pedagógicas, incluso las contemporáneas, han reconocido la importancia de fortalecer conceptos como el de la lectura crítica, pero el proceso lector aún no ha sido considerado a la luz del placer como esencia para formar lectores. De hecho, ya es muy común diferenciar los niveles literal, inferencial y crítico, pero no es frecuente que los propósitos de la lectura crítica, por ejemplo, se logren a través de una actividad que al mismo tiempo sea placentera para los estudiantes.
Una realidad consiste en que para leer no es suficiente el gusto y la motivación. Existen unas necesidades de tipo cognitivo que deben comprometerse. En palabras de Cassany:

Más moderna y científica es la visión de que leer es comprender. Para comprender es necesario desarrollar varias destrezas mentales o procesos cognitivos: anticipar lo que dirá un escrito, aportar nuestros conocimientos previos, hacer hipótesis y verificadas, elaborar inferencias para comprender lo que sólo se sugiere, construir un significado, etc. (21)

No hay duda de que la práctica de la lectura no solo requiere de esos procesos cognitivos, sino que también los fortalece en la medida en que leer sea más habitual. Por esta razón, más que pensar en leer para aprobar un grado que finalizará, tiene que reconocerse que las habilidades mentales no tienen vacaciones y requieren de práctica constante. Este tipo de ideas son las que llevan a presentar como aforismo el que la lectura no se promueve para que el estudiante apruebe los años escolares, sino para que haya un crecimiento intelectual (individual y colectivo), el cual seguramente se reflejará en el plano familiar, social y nacional.

Además de los procesos mentales que entran en juego, hay que considerar la información con la que cuenta el lector. Solé (18) asegura cómo "para leer necesitamos, simultáneamente, manejar con soltura las habilidades de descodificación y aportar al texto nuestros objetivos, ideas y experiencias previas". Con esta postura surge la subjetividad como un elemento que también interviene al leer.

\section{El estudiante como lector}

En principio, la concepción de lector no puede limitarse a la de un sujeto que lee con el fin de aprender algo, para luego responder unas preguntar y aprobar una asignatura. Esa, quizás, es la versión más simple que se pueda tener del estudiante como lector. Una mirada más amplia trasciende lo meramente académico. Un lector, sea o no sea en el rol de estudiante, cumple una tarea teóricamente compleja. Serrano (5) relaciona al lector con el texto, de la siguiente manera:

La lectura, de acuerdo con la perspectiva psicolingüística es vista como un proceso de construcción de significados, para lo cual es absolutamente necesario que se produzca una transacción, una interfusión 
entre el lector y el texto, de la cual ambos resultan transformados. Esta visión del proceso no se centra, ni exclusivamente en el texto, ni en el lector, aunque sí le otorga a este último el papel esencial, que efectivamente desempeña como constructor activo de significados.

También se parte del principio según el cual todo lector maneja un conjunto de conocimientos, creencias e ideologías de los que no se puede desprender cuando lee. De acuerdo con Sánchez, "La comprensión del texto depende, básicamente, del proceso de lectura seguido que siempre implica el reconocimiento del acervo cultural, social y temporal en el que el texto ha sido escrito" (53).

Las dos propuestas anteriores se complementan para comprometer al lector con la construcción de significados, la conexión y la interacción con el texto. Esto solo se logra si el lector participa activamente con todos los recursos psicológicos, cognitivos y mentales que requiere la lectura.

En este apartado vale la pena reflexionar en torno a la importancia del lector. Carvajal (32) es aforístico al decir que "un libro sin lector no sería más que un 'conjunto de manchas negras' sobre un papel. Por ello, podemos concluir, que la razón de ser del documento escrito es el propio lector". Existen demasiados textos esperando a ser revividos por algún lector. Por eso se considera extraño que esa variedad no sea aprovechada en los contextos escolares, con el fin de que los estudiantes tengan más oportunidades de ser lectores por placer y no por trabajo. Las posibilidades de lecturas son ilimitadas y no deben seguir como "manchas negras" en el olvido.

La realidad es que la lectura se limita. Petit lo menciona de la siguiente forma:

Por ello me parece que algunos añoran una lectura que permita delimitar, moldear, dominar a los jóvenes. En los medios de comunicación se oyen lamentaciones como "los jóvenes ya no leen", "hay que leer", o incluso "se debe amar la lectura", lo cual evidentemente ahuyenta a todo el mundo. Se deplora en particular que se pierda la lectura de grandes textos supuestamente edificantes, ese "patrimonio común", como dicen, que es una especie de tótem reunificador en torno al que se supone deberíamos congregarnos. (16-17)

En realidad, Petit reúne las palabras que más se repiten sobre el papel de los alumnos como lectores. Se toma al estudiante como un ser malvado en el mundo de la academia que se reúsa a leer aquello que es necesario en las instituciones educativas. En definitiva, de alguna manera se espera que a todos les guste lo mismo y, en el peor de los casos, aunque les disguste completamente, deban devorar esos textos que siempre se han leído.

También puede hablarse de espacios de formación en los que la lectura no juega ningún papel. Por ello, no es extraño que cuando un estudiante llega a la universidad, la lista de libros que ha leído se pueda contar con los dedos de las manos. Esto no proviene de (ni genera) misterios; basta con preguntarle a un estudiante de undécimo grado cuántos libros ha leído durante los últimos diez años. La respuesta, por lo general, implica que se culpe a los profesores - en especial, al profesor de español-, pues se cree que él es el único responsable de la formación en lectura. Además, cuando el profesor de español pretende fomentar el hábito lector, suele ocurrir que la tradición es más fuerte que en cualquier otro ámbito: se proponen libros como Cien años de soledad, María y El Popol Vuh, entre otros aun más dolorosamente manidos como El Mío Cid. Por razones como estas, dentro del acervo cultural de los profesionales, solamente existe García Márquez como escritor colombiano, pues pareciera que no hubiera otros. Después, se afirma que a los estudiantes no les gusta leer, pero, ¿cuántos de esos jóvenes sentirán gusto por la lectura después de haberse enfrentado a El Mío Cid? ${ }^{1}$

Un primer contraargumento tendría como base la idea según la cual la lectura no puede centrarse únicamente en el gusto, debido a que se correría el riesgo de que solo se leyeran textos sin el nivel de dificultad que se espera para cada uno de los diferentes niveles educativos. En alguna medida, esa refutación tiene bases firmes, pues si no fuera así, en la actualidad la literatura no estaría siendo desplazada por los textos de superación personal o "seudoliterarios". Por esta razón, es muy relevante aclarar que ese goce estético no es ajeno a un ejercicio intelectual que conlleve el crecimiento de los lectores. En palabras de Niño:

Leer obras de los géneros literarios (narrativos, líricos o teatrales) compromete algo más que el puro goce, deleite o recreación (lectura recreativa). Es compenetrarse con las experiencias del autor, a fin de compar-

El autor de este artículo, como lector aficionado, no juzga si este libro es bueno o malo -literariamente hablando-; solamente se conforma con asegurar que no es del gusto de la mayoría de los jóvenes estudiantes. 
tir con él, una nueva forma de ver la realidad y la vida: la expresión estética. Es valorar sus planteamientos, sus actitudes y sentimientos, y los recursos de lenguaje de que se vale para expresarse. Es genialidad de un autor. (148)

Esa concepción de la lectura es un indicio de lo que implica la práctica de ese hábito. Por eso, no es raro que alguien que se caracterice por ser buen lector se destaque en aspectos relacionados con la cultura y la agilidad mental.

Infortunadamente, el hábito de la lectura no siempre es motivo de reconocimiento, sino que, por el contrario, puede estar acompañado de una forma de matoneo académico. Petit (131) lo expone de la siguiente forma: "Con gran frecuencia, en los medios populares, el "intelectual" resulta sospechoso; se le hace a un lado como un paria, se le trata de "lambiscón", de marica, de traidor a su clase, a sus orígenes, etc.”. Más adelante dice Petit:

A continuación les presento los adjetivos atribuidos al alumno que gusta de la lectura por alumnos de liceos técnicos o profesional en Francia: "bufón”, “cerebrito", "lentudo", "hijo (o hija) de papi", alguien que no debe sentirse muy bien en su pellejo, sin personalidad, alguien que se cree más listo que los demás, un enfermo, un trabado, un solitario, alguien que "da flojera”, etc. (133)

Esto constituye otro factor que aleja a los alumnos de la lectura, ya que no se puede desvincular al estudiante del círculo social en el que se desenvuelve. Por lo tanto, al abordar la lectura en el aula, es recomendable arriesgarse a involucrar a todos los discentes. De seguro, incluso el alumno que quiera mostrarse como más insensible, sentirá interés por alguno de los tantos libros que se suman a la historia y el presente de la literatura.

En definitiva, si realmente existe un interés por fortalecer la lectura, tanto el tiempo en el aula como la actitud del maestro deben converger hacia ese propósito. No basta con afirmar que se va a propiciar la lectura, cuando en realidad no se dedica exclusivamente un espacio para eso, un momento en el que el profesor comparte un silencio en el aula mientras las mentes de todos vuelan por las páginas de la imaginación, la creación, los sueños y el placer. Petit (147) asegura que "lo que atrae la atención del niño es el interés profundo que sienten los adultos por los libros, su deseo real, su placer real". En consecuencia, esas clases protagonizadas por la lectura deben ser placenteras tanto para los estudiantes, como para el profesor.

Por último, la posición de Galera (220-221) resume la manera como se espera que se conciba al estudiante como lector:

Al iniciar a los niños en la lectura, debemos contribuir a formar en ellos la competencia lectora y que vayan adquiriendo, al mismo tiempo, el goce estético de los textos literarios, sin olvidar el desarrollo de la capacidad crítica ante cualquier texto literario o no.

El hecho de que haya placer al leer no significa que se dejen de lado otros propósitos tales como los inherentes a la comprensión y a la lectura crítica.

\section{El papel del profesor en los procesos de lectura}

Otra de las tantas generalizaciones del ámbito educativo consiste en que el docente sirve de ejemplo para sus alumnos. Sin embargo, es un comentario arriesgado en la medida en que implica que a todos los profesores les gusta leer y que sus niveles de lectura son los mejores. De momento, surgen dos interrogantes: ¿a todos los profesores les gusta leer?; ¿los docentes que leen son lectores críticos que discuten con el autor de un libro y que ponen en juego sus conocimientos, experiencias, creencias y su visión estética? En lo que respecta a este trabajo, no se dará respuesta inductiva a este interrogante, pero sí se tendrá en cuenta como un factor que interviene en lo que se pretende conocer: la posibilidad de que el placer lleve a los estudiantes a leer.

El maestro puede tener la mejor voluntad para fomentar la lectura, pero no basta con intenciones, ya que los estudiantes requieren de una intervención más concreta y práctica. No es raro que un profesor motive (o por lo menos, lo intente) a sus alumnos a leer, y cuando lo logra empiezan todos a leer un libro, un único libro que se ha leído por décadas porque así lo establecen los textos escolares y la costumbre. Sería como si a todos los adultos los motivaran a practicar algún deporte, y después todos tuvieran que jugar golf. Algunos lo disfrutarán; otros jugarán por cumplir con la cita deportiva y otros preferirán sentarse a observar, mientras añoran practicar el deporte que les gusta.

Por lo anterior, cabe considerar el planteamiento de Bettelheim y Zelan (177): "Los maestros competentes poseen suficientes facultades de observación 
para juzgar lo que puede atraer o repeler al alumno mientras lee y para valerse de tal conocimiento para tratar simultáneamente con varios niños". Puede decirse que "varios" es un eufemismo para la cantidad de estudiantes que suelen ocupar un salón de clase. Esta realidad llevaría a pensar que el profesor tendría que leerse tantos libros como estudiantes hay en el salón, con el fin de poder evaluarlos. Parece que no bastara con que se dedicaran espacios a la lectura y que el momento como tal, la dedicación y el gusto de cada estudiante al leer no fueran suficientes para que se evitara la evaluación del libro. En relación con la cantidad de libros que el profesor tendría que leer, sería como pensar que si algún día sale con sus estudiantes a degustar de un almuerzo a la carta, se vería obligado a probar todos los platos que hayan servido en la mesa, solamente con el objetivo de preguntar qué tan rico estaba el almuerzo y poder cerciorare de que la respuesta de cada uno es correcta. No bastaría con que cada estudiante haya disfrutado su plato.

No obstante, el papel del profesor no se limita al de ser ejemplo de lector por placer. También se espera que tome decisiones en cuanto al manejo de los recursos para la clase. Carvajal se refiere estrictamente al texto escolar:

El estudiante, desde sus primeros pasos como lector, es sometido al "texto escolar". No es llevado a él, previa demostración de necesidad, como medio de enseñanza y aprendizaje. No media en el uso del "texto" la conciencia, sino la costumbre o la regla. El rechazo y el distanciamiento del lector hacia el documento es el resultado, desgraciado por cierto, de este hecho. (25)

Por lo tanto, el docente se ve en la necesidad de acudir a otros libros que no sean los que el estudiante ve como obligatorios. El texto escolar puede ser útil sí se toma como punto de partida o como invitación para conocer algunos libros; de hecho, eso le daría significado al texto escolar.

\section{Metodología}

De manera muy general, el desarrollo de este trabajo se logró por medio de una investigación de enfoque mixto; los resultados son cualitativos, pero esto no excluye la posibilidad de cuantificarlos a la hora de buscar nociones generales en relación con los aspectos que se mencionan en los resultados. El método ha sido el inductivo en la medida en que los resultados obtenidos pueden considerarse generalizables. En cuanto al tipo, se ha considerado la investigación-acción, en razón a que hubo una relación directa con la población a la hora de desarrollar las actividades. La población estuvo conformada por estudiantes de los grados sexto, séptimo y octavo de una institución educativa del departamento de Boyacá.

Para el análisis de los resultados, se utilizó la siguiente entrevista ${ }^{2}$ dirigida a algunos estudiantes:

1. ¿En los años pasados, cuántos libros había leído?; ¿cuáles? (Si la respuesta fue negativa, se les preguntó: ¿por qué no?)

2. ¿Este año cuáles libro ha leído?

3. ¿De esos libros cuál es el que más le ha gustado?

4. ¿Qué ha logrado usted o en qué aspecto cree que ha mejorado después de haber leído esos libros?

5. ¿Usted cree que este año hemos tenido los suficientes espacios para leer?

6. ¿De acuerdo con su experiencia como estudiante, usted considera que todos los profesores de español crean espacios para leer o algunos sí y otros no? (A quienes respondieron que "todos o algunos no", se les preguntó: ¿y por qué cree que todos o algunos no lo hacen?)

7. ¿Le gustaría que en los próximos años sus profesores de español siguieran sugiriendo libros para leer?; ¿por qué?

\section{Resultados y conclusiones}

A manera de muestra, a continuación se incluyen dos entrevistas que permiten reconocer la tendencia de los estudiantes que participaron en el proceso.

\section{Entrevista 1}

Entrevistador: ¿En los años anteriores usted había leído libros?

Alumno: No, señor.

E: ¿Por qué no?

A: Porque allá los profesores no nos decían que leyéramos algún libro o nos ponían de tarea algo sobre los libros.

E: Bueno, ¿este año cuáles libro ha leído?

A: Alicia en el país de las maravillas, El principito, El viejo y el mar, y Los cuentos de Pancho.

E: ¿De esos libros cuál es el que más le ha gustado? A: Alicia en el país de las maravillas.

En cada caso, esta entrevista pudo variar sutilmente de acuerdo con las respuestas de los estudiantes. 
E: ¿Qué ha logrado usted o en qué aspecto cree que ha mejorado después de haber leído esos libros?

A: En la lectura, en la escritura, porque los profesores ahí nos ponen ahí unas palabras que nosotros no sabemos, nos ponen a investigarlas y a escribirlas ahí así.

E: ¿Usted cree que este año en clase de español se ha creado o se ha tenido el espacio necesario para leer?

A: Sí, señor.

E: ¿Cuándo?

A: Los jueves y los lunes y el tiempo que más me gusta es el jueves, porque los jueves es una hora, pero esa hora la aprovechamos mucho.

E: ¿De acuerdo con su experiencia como estudiante, usted cree que todos los profesores de español crean espacios o fomentan la lectura, o cree que ninguno lo hace o cree que algunos lo hacen y algunos no?

A: Algunos lo hacen y algunos no.

$\mathrm{E}$ : ¿Y por qué cree que algunos no lo hacen?

A: Porque no tienen el mismo interés sobre los alumnos.

E: ¿A usted le gustaría que en los próximos años los profesores de español le sugirieran más libros para leer?
A: Sí, señor.
E: ¿Por qué?
A: Porque uno aprende más.
E: Muchísimas gracias.

Las dos primeras respuestas evidencian que el estudiante no había recibido la invitación a leer. De alguna forma, la segunda respuesta lleva a asegurar que los alumnos esperan las instrucciones de los profesores para actividades como la lectura. Al decir que Alicia en el país de las maravillas fue un libro que le gustó, deja ver que la lectura, más allá de haber sido una propuesta en la clase de español, constituyó un momento de placer. La quinta respuesta muestra un mejoramiento consciente en relación con la lectura, apoyado en la idea de que pudo darse a través de los libros que le han gustado. En la séptima respuesta es indudable que la lectura de por sí ya la ha tomado como un momento de gusto y de provecho. Debe reconocerse que si menciona un espacio específico como favorito, entonces significa que le genera algún tipo de placer. La última respuesta se caracteriza por hacer saber que reconoce el aprendizaje por medio de la lectura y, de acuerdo con toda la entrevista, la lectura no la asume como una obligación académica aburridora o que causa hastío.

\section{Entrevista 2}

Entrevistador: ¿En los años pasados usted cuáles libros había leído?

Alumno: Ninguno.

E: ¿Por qué?

A: Porque pues no contaba con el tiempo ni..., o sea contaba pero ya en las clases, pero los profesores no nos ponían a leerlos.

E: ¿Sus profesores de años pasados le habían sugerido algún libro para leer?

A: Nunca.

E: ¿Este año cuáles libro ha leído?

A: Este año he leído El extranjero, la María y La Vorágine.

E: ¿De esos libros cuál es el que más le ha gustado?

A: El extranjero.

E: ¿Qué ha logrado usted o en qué aspecto cree que ha mejorado después de haber leído esos libros?

A: He mejorado en la lectura, en la ortografía y he conocido más palabras.

E: ¿Usted cree que este año en clase de español se ha creado o se han tenido los espacios necesarios para leer?

A: Este año sí.

E: ¿Usted cree que todos los profesores de español fomentan la lectura o ninguno la fomenta, o algunos sí lo hacen y otros no?

A: Algunos sí lo hacen y otros no.

$\mathrm{E}:$ ¿Y por qué cree que algunos profesores no les sugieren a los estudiantes libros?

A: Porque ellos prefieren que aprendan más sobre escritura y pues no se preocupan tanto por la lectura.

E: ¿Le gustaría que en los próximos años los profesores de español le sugirieran más libros para leer o no?

A: Sí, señor.

E: ¿Por qué?

A: Porque como decía ahorita se aprende más sobre ortografía y uno conoce más palabras.

E: Bueno, muchísimas gracias.

En la segunda respuesta es claro que el estudiante ve la clase como un espacio apropiado para leer con el profesor. Esta idea es favorable en el sentido en que el salón de clase se convierte en un lugar que no se 
limita al cumplimiento de las obligatoriedades de la escuela, sino que adquiere el valor de un espacio más real para el estudiante, en el que puede crecer como persona a través de actividades que sean placenteras, como la lectura. La sexta respuesta, al igual que en la entrevista anterior, es un indicio del mejoramiento en asuntos de bastante relevancia, tales como la lectura y la ortografía. Sin duda, en este momento se puede reafirmar que el conocimiento y uso de la lengua se ven favorecidos por la lectura, como actividad intelectual y de placer. La novena respuesta lleva a repensar la posición que ha ocupado la lectura en el ámbito académico, puesto que pareciera que los temas por ver la han desplazado completamente.

Como conclusión, se puede sostener la posibilidad de que la lectura ocupe un lugar protagónico en la formación de las personas. Esto no significa que los docentes deban diligenciar más documentos para que en la teoría la lectura haga milagros, sino que la lectura como tal se haga presente. Leer por leer y por placer. Ya se ha visto que si el objetivo se centra en el aprendizaje, entonces debe considerarse seriamente la consciencia del mejoramiento que tienen los estudiantes cuando son lectores. No obstante, vale la pena fortalecer la idea según la cual la exigencia intelectual de la lectura no debe responder limitadamente a las intenciones escolares, sino a la creación de una costumbre, que conlleva más habilidades mentales.

Ahora la lectura debe enfrentarse a unos placeres que no requieren ningún tipo de concentración, tales como los inherentes a las redes sociales. Por tal razón, lo que se lee, o se propone para leer, también debe atraer la atención, pues sobraría preguntar qué escogería una persona si a un lado tiene una actividad que le gusta y al otro, una que lo aburre. En este punto casi final, se sabe que una de las ventajas de la lectura, en esa disputa de placeres, es precisamente que lleva al mejoramiento de algunos aspectos del uso de la lengua, pues así lo demuestran las entrevistas. Los jóvenes en su rol de estudiantes quieren leer, y esa es una realidad que permite soñar con un país culto y socialmente avanzado. Quizá llegue el día en el que el libro (impreso o electrónico) remplace a las redes sociales.

En definitiva, es claro que el estudiante no ve la lectura como una actividad que le disguste, sino que muestra agrado por las horas dedicadas exclusivamente a leer.

\section{Referencias}

Bettelheim, Bruno y Karen Zelan. Aprender a leer. Barcelona: Grijalbo Mondadori, 1997. Impreso.

Carvajal, Lizardo. La lectura. Metodología y técnica. Cali: Feriva, 1994. Impreso.

Cassany, Daniel. Tras las líneas. Sobre la lectura contemporánea. Barcelona: Anagrama, 2006. Impreso.

Galera, Francisco. "La lectoescritura: métodos y procesos". Didáctica de la lengua y la literatura para primaria. Coord. Mendoza, Antonio. Madrid: Pearson Educación, S.A, 2003. 217-261. Impreso.

Niño, Víctor Miguel. Competencia en la comunicación. Bogotá, D.C.: Ecoe ediciones, 2006. Impreso.

Ordóñez, Daniel. Técnicas de lectura rápida y eficiente. Bogotá, D.C.: Alethia, 1995. Impreso.

Petit, Michele. Nuevos acercamientos a los jóvenes y la lectura. México, D.F.: Fondo de Cultura Económica, 1999. Impreso.

Sánchez, Jesús. (coord.). Saber escribir. Madrid: Instituto Cervantes, Aguilar, 2006. Impreso.

Serrano, Stella. El aprendizaje de la lectura y la escritura como construcción activa de conocimientos. Conferencia pronunciada en el Simposio Internacional de Educación en la Diversidad "porque todos somos diferentes", celebrado en Panamá, 28 al 30 de enero de 2000. Web. 2014.

Solé, Isabel. Estrategias de lectura. Barcelona: Grao, 1992. Impreso. 